\title{
Inclusion of forestry offsets in emission trading schemes: insights from global experts
}

\author{
Anil Shrestha ${ }^{1} \cdot$ Sarah Eshpeter $^{1} \cdot$ Nuyun $\mathrm{Li}^{2}$. \\ Jinliang $\mathrm{Li}^{3} \cdot$ John O. Nile ${ }^{4}$ Guangyu Wang ${ }^{1}$
}

Received: 1 January 2021 / Accepted: 10 March 2021 / Published online: 2 May 2021

(C) The Author(s) 2021

\begin{abstract}
Emissions trading schemes (ETSs) have been a central component of international climate change policies, as a carbon pricing tool to achieve emissions reduction targets. Forest carbon offset credits have been leveraged in many ETSs to efficiently meet emission reduction targets, yet there is little knowledge about the perceptions, experiences, and challenges associated with the forest carbon offsetting in existing and pilot ETS. Given that the future inclusion of forest carbon offset in ETS management activities and policies will require strong support and acceptability among the institutions and experts involved in ETS, this study explores the experiences and lessons learned with 16 globally engaging experts representing major existing ETSs (North America, Europe, and New Zealand) and Chinese pilot ETSs towards the inclusion of forestry offsets, major concerns and challenges with existing implementation models. Findings revealed that many respondents particularly from North America, New Zealand, and Chinese pilot
\end{abstract}

Project funding: The project was funded by the China Green Carbon Foundation and the Faculty of Forestry, University of British Columbia.

The online version is available at http://www.springerlink.com

Corresponding editor: Yu Lei

Guangyu Wang

guangyu.wang@ubc.ca

1 Asia Forest Research Centre, Faculty of Forestry, University of British Columbia, Vancouver, BC V6T 1Z4, Canada

2 China Green Carbon Foundation, Beijing 100714, People's Republic of China

3 Chinese Institute Green Carbon, Beijing 100029, People's Republic of China

4 The Carbon Institute, San Diego, CA 92103, USA systems portrayed positive attitudes toward the inclusion of forestry carbon offsets and its role in contributing to a viable ETS, while European experts were not supportive. Respondents cited leakage, permanence, additionality, and monitoring design features as the major challenges and concerns that inhibit the expansion and inclusion of forest carbon offsetting. Respondents from Chinese pilot schemes referenced a unique set of challenges related to implementation, including the increasing cost of afforestation and reforestation projects, the uncertainty in the future supply and demand for their national Certified Emissions Reduction (CER) scheme and landowner engagement. Existing and future ETSs should learn from and address the challenges experienced by global experts and carbon pricing mechanisms to design, evaluate, or enhance their forest carbon offset programs for an effective and viable system that successfully contributes to GHG mitigation practices globally. We recommend inclusion of forest carbon offsets at the early stages of ETS improves the perceptions and experience of policy makers and practitioners toward the success and potential of forestry offsets in ETS ensuring familiarity and confidence in the mechanism.

Keywords Emission trading scheme $\cdot$ Forest carbon offsets $\cdot$ Climate change $\cdot$ Cap and trade $\cdot$ Carbon

\section{Introduction}

The increasing concentration of atmospheric greenhouse gases (GHGs) and consequent climate change is an urgent global issue with potentially catastrophic impacts on societal and environmental systems. The reduction of GHG emissions has been a central component of international climate change policies over the last two decades, and carbon pricing has been recognized as a key element of national strategies 
to tackle climate change (Johannsdottir and McInerney 2016). In efforts to develop an international mechanism to achieve emissions reductions, emissions trading schemes (ETSs) were popularized by the Kyoto Protocol in 2005 as a solution to effectively limit global temperature rise (UN 1998; Roppongi et al. 2016; Kossoy 2015; UNFCCC 2015a). An ETS is a market-based approach to reduce GHG emissions that provides economic incentives for achieving emissions reductions. Under ETSs, a government places a cap on aggregate emissions for equivalent tons of $\mathrm{CO}_{2}$ and then issues permits (or allowances) for participating entities to use or trade the permits (Ellerman et al. 2010; Doda 2016). These permits or allowances are tradable in the carbon market created by the cap, setting a market-based price per unit of pollution that provides an incentive for emissions reductions (Ellerman et al. 2010).

Cap-and-trade is the backbone of ETSs that have been implemented at various levels globally (Roppongi et al. 2016). Since the establishment of EU ETS in 2005, as of 2020, 31 cap-and-trade emissions trading programs have been implemented and scheduled for implementation with regional, national, and subnational applications representing $17.0 \%$ of global GHG emissions (World Bank 2020). The turnover in global emissions trading has also been increasing, for instance, it was 34\% up ( $\$ 214$ billion) in 2019 compared to 2018 with EU ETS making up $80 \%$ of the traded volume (Refinitiv 2019). The surge of emission trading was also observed in two regional North American ETS and Chinese pilot ETS (now a national ETS) (Refinitiv 2019). International carbon markets such as these have been appealing and increasingly successful in regulating carbon emissions. EU ETS was able to save about 1.2 billion tons of $\mathrm{CO}_{2}$ between 2008 and 2016, which is almost half of what EU governments promised to reduce under their Kyoto Protocol commitments (Bayer and Aklin 2020)-indicating ETS as an important policy tool to regulate global carbon emission.

With GHG reduction efforts at the forefront of international policy, attention has turned to the use of forests for carbon sequestration (Ristea and Maness 2009; Gaast et al. 2018). This is because the global forests provided a net carbon sink that absorbed twice as much $\mathrm{CO}_{2}$ (16 billion metric tons per year) as they emitted each year (8.1 billion metric tons per year) between 2001 and 2019 (Harris et al. 2021). Most of the emission has been reported due to deforestation and other disturbances (Harris et al. 2021).

Of all global economic sectors evaluated by the Intergovernmental Panel on Climate Change (IPCC), forests play an important role as a carbon sink by sequestering atmospheric $\mathrm{CO}_{2}$ and storing it in biomass through photosynthetic processes (IPCC 2007; Ristea and Mannes 2009). While estimates vary, forest conservation, forest restoration and improved forest management in tropical countries can deliver approximately 5-6 billion metric tons per year of $\mathrm{CO}_{2}$ in near-term at cost effective levels, economicallycompetitive mitigation potential (Griscom et al. 2020). Forest and related natural climate solutions are appealing and have the potential to provide the most cost-effective solution to carbon sequestration in comparison to other carbon capture technologies (Griscom et al. 2017; Fargione et al. 2018). Emissions reductions associated with forestry projects are eligible for generating carbon credits for purchase on the ETS market platform, allowing emitters to offset their emissions while buying time to enable them to develop and adopt emission-reducing technologies, as practiced in several active and pilot schemes (Kooten 2017).

The Paris Agreement on climate change in 2015 emphasized negative emissions (i.e. taking $\mathrm{CO}_{2}$ from the atmosphere) and the potential contributions of the conservation and restoration of sinks and reservoirs of greenhouse gases, including forests to effectively limit global temperature rise below $2{ }^{\circ} \mathrm{C}$ relative to pre-industrial levels while pursuing efforts to limit warming to $1.5^{\circ} \mathrm{C}$ to avoid the most severe impacts of climate change (UNFCCC 2015b). In 157 countries' Nationally Determined Contributions (NDCs), an important mitigation measure in post-2020 climate plans, forests are the second most referenced sector for targets (other than those for reduced greenhouse gas emissions) (FAO 2016), and majority of countries (62\% of NDCs) refer to restoration, forest management and protection of natural forests and/or tree plantations as key land-based actions for mitigation purposes (Seddon et al. 2019). The scope of inclusion of forest activities in ETS becomes even more important with improving methodologies for carbon accounting in forestry projects addressing uncertainties and mitigation risk as well as recent international/national commitments to carbon sequestration and ecosystem services through pledges to reforest millions of hectares, such as the New York Declaration of Forests (NYDF), Bonn Climate Challenge, the UN Decade of Restoration and the Trillion Tree Initiative.

Currently, forest carbon offset credits have been leveraged in several carbon pricing systems as an opportunity to meet compliance with their targets. Forestry carbon offset has been included in existing ETS systems such as California (Anderson et al. 2017) and New Zealand (Manley and Maclaren 2012) as well as in Chinese Pilot ETS (Zhang 2015a, b). Though forestry carbon offset has not yet been included in EU ETS, forest carbon credits may likely enter the EU ETS in future (Meyer-Ohlendorf et al. 2016). Indeed, forestry sector credits made up about $42 \%$ of all credits issued last five years in global carbon pricing initiatives (World Bank 2020). Despite this known potential of forests to provide viable offset opportunities for emissions trading schemes, there is little research about the perceptions, experiences, and challenges associated with forest carbon offsetting in existing and pilot ETSs. Understanding 
these key aspects of forest offsetting mechanisms is pertinent in the current and future context of GHG emissions reduction policies globally, which will contribute to the efficient inclusion and implementation of forestry offsets in global climate change mitigation efforts and carbon pricing schemes. Given that the future inclusion of forest carbon offset in ETS management activities and policies will require strong support and acceptability among the institutions and experts involved in ETS, this study reports on the experiences and lessons learned in regard to the international practice of forestry inclusion within ETSs through in-depth expert interviews in existing and pilot ETS.

\section{Methods}

This study is a part of a broader carbon market research project that aims to identify the successes, challenges, and perceptions of carbon market implementation to inform future market development and the potential for global carbon market linkage. Experts were interviewed totalling sixteen interviews representing five major global carbon markets (established markets namely Europe, California, New Zealand, Quebec and Ontario), in addition to five Chinese pilot schemes (Fig. 1). Except for EU ETS, all other ETS include some form of carbon forestry offset in their scheme. For the interview, we first contacted the relevant carbon trade institution in the related jurisdiction requesting their interest to participate in our research. The respective organization recommends its representative and then we set up an in-depth interview with the experts. Hence, experts' opinions represent not only their knowledge and experience but also their affiliated institutions. A set of pre-interview packages were distributed to the expert participants at least one week prior to the interview. The package provided background information on global carbon markets, the purpose of the study, as well as interview questions. Experts involved in the interview have high levels of knowledge and experience in their ETS development with varying capacities of involvement ranging from regulation and legislation, finance and auctioning, offsetting, and third-party informative organizations.

Nearly all interviews were conducted in-person for averaging about $60 \mathrm{~min}$, however few interviews (including New Zealand, and Quebec interviews) were conducted remotely due to logistical challenges. The main interview questions for a broader carbon market research project were separated into the following four themes: (1) overview and experience in the ETS (seven questions), (2) experience and opinion regarding forestry contributions to the carbon market (two questions), (3) potential for linkage of their ETS to the global carbon market (seven questions), and (4) potential for linkage to specifically the Chinese pilot schemes (four questions). All interview questions were open-ended and were often followed by open-ended questions to allow for a tailored response based on the individual(s) experiences, challenges, and opportunities in their respective ETS. For the purpose of this study responses on the experience and opinion regarding forestry contributions to the carbon market (second thematic area of interviews) were analyzed, exploring the perceptions and experiences of forestry contributions to the carbon market.

Interviews were recorded, transcribed, and formatted in Microsoft Word compatible for NVivo analysis. NVivo is a qualitative computing software, with the ability to manage, access, and analyze qualitative data (Bazeley and Richards 2000; Woolf and Silver 2017; NVIVO n.d.). Interview questions were analyzed to explore key perceptions and challenges regarding the inclusion and contributions of forestry
Fig. 1 Interview of Global ETS institutes and representatives

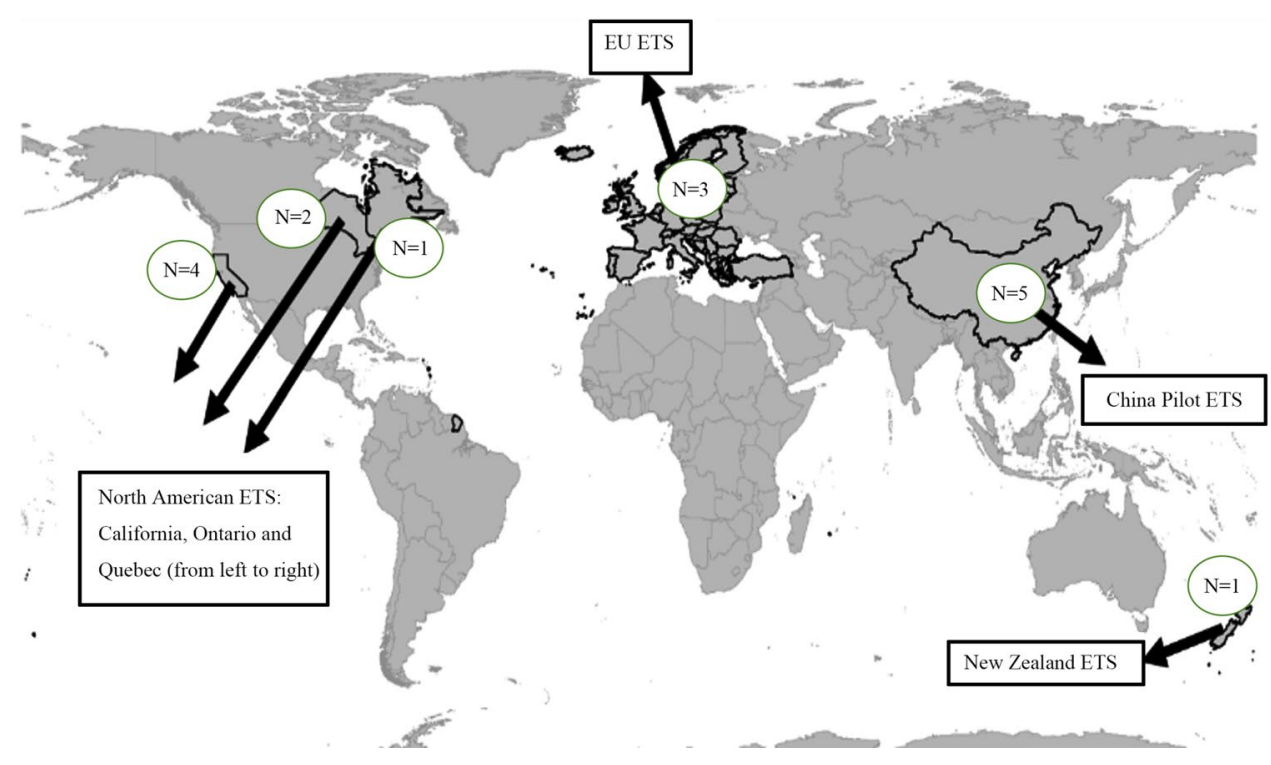


to the carbon market, facilitating a qualitative analysis of expert interviews that highlights the emerging thematic framework in professional opinions and experience. Interview questions were individually analyzed using a qualitative thematic analysis (TA) approach, which helps for uncovering themes and patterns that emerge in a dataset focused on a generalized topic (Braun and Clarke 2014).

Using a TA approach, initial codes were generated for significant comments or pieces of information for each expert's response to an interview question. Initial codes were placed in an Excel sheet where similar responses (i.e. sharing words or phrases, expressing similar sentiments) were categorized into themes (Meyer and Avery 2009; Crocker et al. 2014; Bree and Gallagher 2016; Nowell et al. 2017). The frequency of thematic areas was recorded. Multiple rounds of analysis were conducted for several interview questions, combining similar themes or separating them into two if small but critical differences in response were noted. Through this method of TA, interview responses were coded allowing for themes to emerge from within the data as opposed to through leading, pre-determined questions, ensuring no observer bias or preferential coding (Charmaz 1990; Crocker et al. 2014). Nodes for emergent themes were created in NVivo to store reference snippets of transcribed interviews that relate to the respective theme, which can be viewed in the full-length transcribed interview for context.

While presenting and analyzing interview responses, Chinese pilot ETSs were observed separately from the remaining ETSs represented in interview responses due to notable differences in duration of carbon market function and experience. Accordingly, results were presented and compared between the two groups. Emergent themes and their associated frequencies were used to inform meaningful trends, insights and detail analysis and discussion related to the use and potential for the contributions of forestry to the global carbon market.

\section{Results and discussion}

\section{Forestry offsets among interviewed schemes}

The forestry offset theme ranked seventh out of the ten most discussed topics or themes from the expert interviews representing the perceptions and popularity among North American (California, Ontario, Quebec), New Zealand, European markets, and the eighth among Chinese pilots ETSs. Observing interview themes and discussions by region, forestry carbon offsets' discussion significantly varied by interview (Fig. 2).

New Zealand followed by Chinese pilots and North American ETS experts contributed substantially more

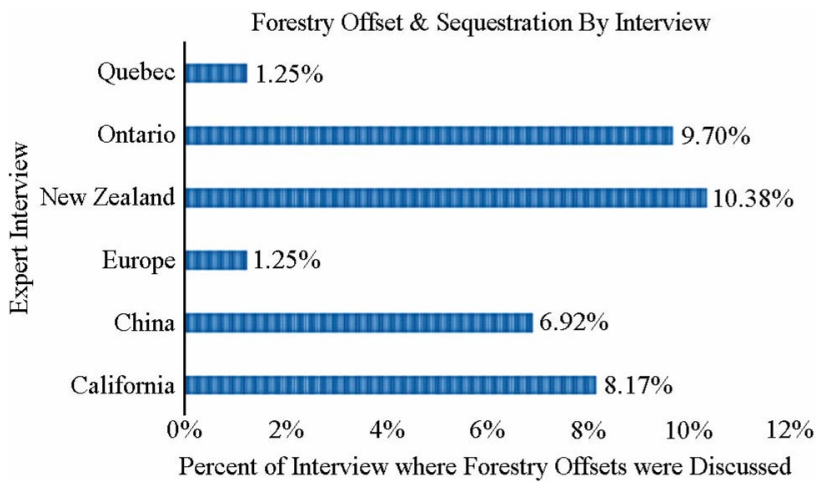

Fig. 2 Proportion of the expert interviews dominated by conversation and discussion surrounding forestry offsets

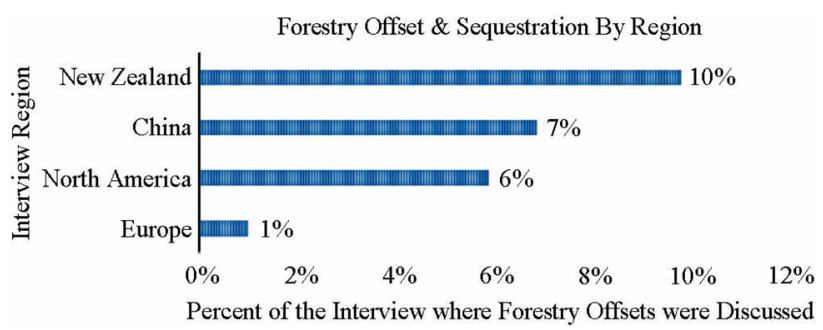

Fig. 3 Proportion of expert interview dominated by conversation and discussion surrounding forestry offsets by region

feedback on forestry offsets in comparison to their European counterparts (Fig. 3).

\section{Experts' attitude and perception of from established ETS towards the inclusion of forestry offsets}

Respondents from the New Zealand ETSs as well as the majority of respondents representing the California ETS portrayed a positive perception regarding the importance of forest-related offsets in their markets. Respondents with positive perceptions cited forestry offsets as a fundamental component in their ETS not only because it ensures the use of all available options for carbon emissions reduction, but also to incorporate a critical economic sector that would not otherwise be covered by an ETS. Forest carbon offsets were referenced as a mechanism to ensure that sectors not covered by the ETS can also be included in incentivizing emissions reductions and improving technology.

Endorsement of forestry offsets in these ETSs is likely shaped by experts' exposure to forest carbon offsetting within their respective ETS. For instance, the California system is America's first legally enforceable compliance offset program for existing forests, allowing emitters to purchase forestry offset credits to meet up to $8 \%$ of their emissions allowances from improved forest management activities 
on privately owned land that enhance carbon sequestration (Anderson et al. 2017). As of 2017, certified forests across the US have provided an estimated 4.4 million tons of carbon dioxide equivalent through forest offsets under the California ETS, totalling 1\% of carbon emissions (Anderson et al. 2017). Similarly, New Zealand being the first ETS to include forestry allows for the trading of forestry generated carbon offset credits to comply with emissions obligations (Manley and Maclaren 2012). As of June 2018, an estimate of 325,307 ha of forest was registered in the ETS representing almost half of the all the post-1989 forest land, which are considered to be new carbon sinks eligible in the NZ ETS to earn units for that carbon storage (New Zealand Forest Statistics 2019).

Interview responses also indicated that forest carbon offsetting is perceived as a more cost-effective solution than other forms of carbon offsets, such as investment in renewable energy, energy efficiency, and capture and storage technology. Respondents further expressed the potential for inclusion of internationally forestry offsets in their systems, however domestic priority (i.e. inclusion of forest in their own jurisdiction) was emphasized in terms of integration into the systems. Baranzini et al. (2018) reported similar public resistance to the use of carbon credits and carbon offsets associated with GHG abatements in foreign countries. Concerns over the displacement of local environmental benefits such as improved air quality in the jurisdiction of the ETS were cited throughout interviews as a potential drawback to including international forestry offsets in an ETS. However, with plans and targets for many countries and other jurisdictions to achieve carbon neutrality in future years, the scope and expansion of the incorporation of international forestry offsets in carbon pricing schemes are very likely (Baranzini et al. 2018). Endorsement of the recently developed California Tropical Forest Standard by the California Air and Resources Board (CARB) is a groundwork effort to support implementing a scaled approach that reduces deforestation and degradation of tropical forest and incentivizes responsible action and investment (CARB 2019). Under this scheme, polluters in California, such as electric utilities, oil refineries and others can offset their GHG emissions by paying governments in tropical forest areas for conservation of forest and carbon sequestration (CARB 2019).

\section{Challenges and barriers from established ETS to inclusion of forestry offsets}

Comparatively, respondents from the European Union ETS expressed concerns regarding the integration of forest carbon offsets. Concerns around leakage, permanence, additionality, and the complexity of forest carbon accounting were referenced as major challenges for inclusion of forest carbon offsetting by both American and European respondents.

Carbon leakage describes the phenomenon that occurs when emissions or emissions reductions transfer from regulated to unregulated regions (Fell and Maniloff 2018). Respondents have concerns about offset credits being allocated to entities outside of the regulated jurisdiction under the ETS such that emissions reduction benefits are not realized within their ETSs. Leakage can occur for a multitude of reasons such as asymmetrical carbon policies, lack of comprehensive coverage, and displacement of activities to another region due to land-use changes or market forces (Kossoy 2015).

Other important challenges discussed by respondents included the issue of permanence of sequestered forest carbon or avoided emissions for which offsets credits are given. The permanence of forest carbon offsets and associated sequestration may be compromised by potential natural (e.g., wildfire, insect damage) and anthropogenic (e.g., logging) disturbances leading to unexpected and unavoidable carbon emissions that could discredit offsets and lead to weakened emissions targets (Parker et al. 2014). Expert respondents cited political pressures and changes in policy as the primary factors inhibiting the permanence of sequestration and avoided emissions associated with forestry offsets. Respondents further expressed their concerns regarding the additionality with reference to the integration of forestry offsets into emissions trading. Effective demonstration of additionality is critical to ensuring the effectiveness of GHG reductions through forest carbon offsetting, proving that emissions reductions would not have been achieved without the offset credit (Richards and Huebner 2012). Several carbon offset registries use buffers where they set aside a certain percentage of forestry-related emissions reductions in a reserve that is accessed to refill any offsets that are lost due to disturbances.

Interview respondents raised the issue on accurate carbon accounting and monitoring, as well as the high transaction costs associated with forest offset projects, especially in terms of measuring, monitoring, reporting, and verifying (MMRV). Other challenges such as differences in governance and legislation amongst jurisdictions were referenced as perceived challenges to incorporating international forestry offsets into their respective systems.

A low price of carbon concerned many interview respondents, which fails to incentive emissions reductions and hinders enabling emissions regulations and practices. For example, the low price per ton of $\mathrm{CO}_{2}$ in the Regional Greenhouse Gas Initiative (RGGI), the first cap-and-trade program in the US, failed to attract forest owners to create offset opportunities (Daniels 2010). Instead, landowners would participate in the carbon market only when the offset price reaches a certain threshold that is beneficial to them 
(Daniels 2010). A respondent from the California scheme stated that many entities did not use offsets to comply due to low prices and significant transaction costs. The respondent continued to note that smaller firms are less likely to partake in forest carbon offsetting, whereas for bigger firms with huge obligations, offsets can be a valuable option. While lack of a consistent carbon price signal and sporadic demand along with high transaction costs has been recognized as the barriers for forestry carbon offsets (and offsets in general), property characteristics such as stocking level, forest type and size, silvicultural treatment and protocol and legislative requirements also influence the financial viability of the forest carbon project and participation of landowners in the compliance forest offset projects in California's Air Resource Board (Kerchner and Keeton 2015).

Finally, a general lack of communication and information sharing between different government levels, for instance between federal and provincial jurisdictions, was referenced by a respondent as a challenge that discourages participation of the lower levels of government. They continued to warn that a lack of clarity around offsetting policies and general lack of information between different scales of government could even lead to additional risks of double-counting an offset.

\section{Attitude and perception of Chinese experts towards inclusion of forestry in ETS}

Experts interviewed from the five Chinese pilot ETSs collectively portrayed positive perceptions toward the inclusion of forestry and its role in viable ETS. Forest carbon sequestration was cited as having a unique role and advantages in carbon trading, achieving ecologically sustainable development and addressing climate change in interviews with the pilot schemes.

China has a strong history of forest carbon trade with many afforestation and reforestation projects in operation, most of which are registered with Clean Development Mechanism (Forest Carbon Asia 2013), likely influencing the perception of local experts. Additionally, policymakers in China have a motivation for successful "carbon forests" (the forests planted and managed for carbon sequestration following specially designed technical provisions or methodologies) while investors have a positive attitude towards its profitability (SFA 2014). The confluence of motivation by both policy officials and investors in the Chinese systems supported the inclusion of forestry in the Chinese pilot systems. For example, in the Beijing pilot system more than $70,000 \mathrm{t}$ of $\mathrm{CO}_{2}$ equivalent has been sequestered through a number of forest carbon sequestration projects.

Respondents further elaborated the importance of the forest in promoting market activity and reducing the enterprise costs of carbon emissions quota management, while supporting the national eco-compensation mechanism and China Certified Emission Reductions (CCERs). Guangdong Changlong Carbon Sink Forestation Project was the first forest carbon project eligible for Chinese Certified Emission Reduction (CCER) credits (Xiaodong 2016). This was verified by the National Development Reform Commission (NDRC) with carbon credits purchased by Yuedian Corporation, priced at a value of 20 yuan/metric tons in June 2016 (Xiaodong 2016; Li 2016).

Benefits to forestry offsets as a certified emissions reduction (CER) were addressed by respondents as a way to improve market activity, reduce enterprise costs associated with carbon emissions quota management, while stimulating forestry enterprise revenue. On the other hand, they continued that sustainable forest management can be achieved through the beneficial exploration of market mechanisms to further improve forest ecological benefits compensation programs. These forest carbon projects support the China Certified Emission Reduction (CCER) projects in the near future.

Respondents suggested that the inclusion of forestry offset should be a mandatory mechanism in ETS design and should be included at an early stage for its success in the long run. They further added that inclusion of forestry is not only beneficial for maintaining biodiversity and reduction of carbon emissions, but also carbon forest projects can and will continue to play an important role in reducing poverty in the region. To elaborate, a respondent explained forest carbon projects promote ecologically rich, economically poor areas in such a way that the project integrates local ecological compensation mechanism so that these projects can be used as low carbon poverty alleviation paths. Moreover, the respondent also suggested inclusion of forestry offset may expand the CCER market and support afforestation and reforestation particularly funding.

\section{Challenges of forestry inclusion in Chinese pilot ETSs}

Although perceptions towards forest carbon offsetting were promising in the Chinese pilot systems, as of 2016 less than 2\% (3.5 million ha) of the total forest area in China (Zhou et al. 2017) was established as the forests planted and managed for carbon sequestration following specially designed technical provisions or methodologies (SFA 2010). Challenges of the inclusion of forestry offsets listed by respondents (and re-iterated in the literature) include the increasing costs of afforestation and reforestation projects and potential disputes between landowners and forest carbon project developers consistent with the findings of Zhou et al. (2017).

Increasing cost of afforestation and reforestation for forest carbon projects is attributed to the higher required transaction costs incurred, including project design and validation, carbon accounting, and monitoring for the entire project 
compared to the non-carbon forests. In addition to the transaction cost, the increasing cost of carbon forests has been attributed to the quality of land, as most of these forests have been planted in barren and unproductive mountain areas located in remote places resulting increased cost of producing CCER by afforestation and reforestation (Zhou et al. 2017).

Other practical challenges faced by forestry offsets in China are attributed to the lack of active participation and consultation with landowners in terms of design and benefit sharing negotiation where forest carbon projects have been developed. Collectively, this has resulted in disputes between landowners and project developers, causing landowner's dissatisfaction with the carbon forest project. A few studies in Guangdong reported that as much as 63\% (Zhou et al. 2017) to $80 \%$ (Fang and Gao 2015) of landowners involved in the carbon forest did not know about the carbon forest, as they (farmers) were not involved in designing the project nor in the benefit sharing arrangement of the project. Often the project developer selects the species to be planted, and decides the arrangement of the benefit sharing in such a way that the CCER credits from the forest belong to the project developer, whereas the benefit from the timber produced from the forest belongs to the landowner (Zhou et al. 2017). For instance, the project developers' preferred local broadleaved tree species such as Schima spp, Castonopsis fissa species in Guangdong, in contrast most of the landowner preferred to plant species such as Cunninghamia lanceolate and Pinus massoniana, which provide better short term economic benefit to the farmers (Zhou et al. 2017). Such conflict between the landholders and project developers may hinder the viability of this climate change mitigation policy.

Though the Chinese respondents did not specifically raise the issue of the lack of uncertainty in future demand and supply for China Certified Emission Reduction (CCER), this could be a potential challenge to the inclusion of forestry offsets in carbon trading (Zhou et al. 2017). Under the Chinese pilot ETSs, for instance, there is a limitation on the use of CCER credits for capped entities, ranging from 5 to $10 \%$ of their total compliance obligation (Zhou et al. 2017), limiting the potential for growth and expansion.

\section{Conclusion}

Overall, North American and New Zealand experts portrayed cautiously optimistic attitudes towards the inclusion of forestry in their respective ETS, however respondents from the EU ETS were skeptical regarding the potential for inclusion in their system as well as the general effectiveness of these offsets. Experts from the Chinese pilot systems, on the other hand, were enthusiastic toward forest carbon offsetting in China and suggested that forest carbon offsetting should be a mandatory mechanism for a robust carbon market. Collectively, perceptions of carbon market experts have been shaped by the current capacity and experience of their system to include forest carbon offsets.

Respondents from North America, New Zealand, and European markets raised similar concerns and challenges associated with forest carbon offsetting, focusing primarily on how issues of leakage, permanence, additionality, and monitory, reporting, and verification (MRV) will be upheld with incorporation into their systems. In contrast, Chinese experts mainly emphasized the practical challenges experienced implementing the forest carbon projects, focusing on increasing costs of afforestation and reforestation projects, a disconnect between realized benefits between landowners and project developers, and uncertainty in future CCER supply and demand.

This study investigated the perceptions, attitudes, and challenges experienced by experts participating in established ETSs globally and revealed that while the incorporation of forestry offsetting embodies great GHG reduction potential, there are design and implementation challenges that should be addressed to ensure viable systems. The study highlighted the political appetite to explore and continue forest carbon offsetting within carbon market development and function as well as the challenges related to risks and uncertainties of forestry offsets in ETSs that need to ensure the permanence of $\mathrm{CO}_{2}$ reductions, minimize leakage from forest offset projects, develop robust MRV, and engage landowners. It appears that perceptions toward the success and potential of forestry offsets are related to the experience and duration of incorporation into the ETS, emphasizing the need for new ETS designs to include forest carbon offsets in the early stages of development to ensure familiarity and confidence in this mechanism. Given the provision of NDCs under the Paris Agreement and urgent global need for GHG emissions reductions, the future of forestry offsets with improved design and implementation features holds the potential to become a critical mechanism in global carbon and climate change mitigation policies.

Acknowledgements We would like to thank China Green Carbon Foundation for the financial support, and also we deeply appreciate the support from the carbon markets in California, Quebec, Ontario, European Union, New Zealand, as well as Hubei, Shanghai, Beijing, Guangdong and Shenzhen carbon markets in China during our interview process.

Open Access This article is licensed under a Creative Commons Attribution 4.0 International License, which permits use, sharing, adaptation, distribution and reproduction in any medium or format, as long as you give appropriate credit to the original author(s) and the source, provide a link to the Creative Commons licence, and indicate if changes were made. The images or other third party material in this article are included in the article's Creative Commons licence, unless indicated otherwise in a credit line to the material. If material is not included in the article's Creative Commons licence and your intended use is not 
permitted by statutory regulation or exceeds the permitted use, you will need to obtain permission directly from the copyright holder. To view a copy of this licence, visit http://creativecommons.org/licenses/by/4.0/.

\section{References}

Anderson CA, Field CB, Mach KJ (2017) Forest offsets partner climate-change mitigation with conservation. Front Ecol Environ 15(7):359-365

Baranzini A, Borzykowski N, Carattini S (2018) Carbon offsets out of the woods? Acceptability of domestic vs. international reforestation programmes in the lab. J For Econ 32:1-12. https://doi. org/10.1016/j.jfe.2018.02.004

Bazeley P, Richards L (2000) The NVivo qualitative project book. Sage, London

Braun V, Clarke V (2014) What can "thematic analysis" offer health and wellbeing researchers? Int J Qual Stud Health Well-being. https://doi.org/10.3402/qhw.v9.26152

Bayer P, Aklin M (2020) The European Union emissions trading system reduced $\mathrm{CO}_{2}$ emissions despite low prices. PNAS 117(16):8804-8812

Bree R, Gallagher G (2016) Using microsoft excel to code and thematically analyses qualitative data: a simple, cost effective approach. All Ireland J Teach Learn Higher Educ 2811-2814.

California Air Resources Board (CARB) (2019) California tropical forest standard. Press Release. https://ww3.arb.ca.gov/cc/ghgse ctors/tropicalforests.htm. Accessed 21 Apr 2020.

Charmaz K (1990) 'Discovering' chronic illness: using grounded theory. Soc Sci Med 30(11):1161-1172

Crocker T, Besterman-Dahan K, Himmelgreen DA, Castañeda H (2014) Use of semi-structured interviews to explore competing demands in a prostate cancer prevention intervention clinical trial (PCPICT). Qual Rep 19(48):1-16

Daniels TL (2010) Integrating forest carbon sequestration into a capand-trade program to reduce net $\mathrm{CO} 2$ emissions. J Am Plann Assoc 76(4):463-475

Doda B (2016) How to price carbon in good times... and bad! Wiley Interdiscip Rev Clim Change 7(1):135-144

Ellerman DA, Convery F, Christian DP (2010) Pricing carbon: the European Union emissions trading scheme. Cambridge University Press, Cambridge

Fang X, Gao L (2015) Construction of valuation index system for carbon forest in Guangdong Province. Guangdong Agric Sci 42:157-162

FAO (2016) The agriculture sectors in the Intended Nationally Determined Contributions: analysis, by Strohmaier R, Rioux J, Seggel A, Meybeck A, Bernoux M, Salvatore M, Miranda J. and Agostini A. Environment and Natural Resources Management Working Paper No. 62. Rome.

Fargione JE, Bassett S, Boucher TM, Bridgham SD, Conant RT, Cook-Patton SC et al (2018) Natural climate solutions for the United States. Sci Adv 4(11):eaat1869

Fell H, Maniloff P (2018) Leakage in regional environmental policy: the case of the regional greenhouse gas initiative. J Environ Econ Manag 87:1-23

Forest Carbon Asia (2013) Forest carbon projects. http://www.fores tcarbonasia.org/activities/forest-carbon-projects/. Accessed 11 Oct 2019.

Gaast WVD, Sikkema R, Vohrer M (2018) The contribution of forest carbon credit projects to addressing the climate change challenge. Clim Policy 18(1):42-48. https://doi.org/10.1080/14693 062.2016 .1242056
Griscom BW, Adams J, Ellis PW, Houghton RA, Lomax G, Miteva DA et al (2017) Natural climate solutions. PNAS 114(44):11645-11650

Griscom BW, Busch J, Cook-Patton SC, Ellis PW, Funk J, Leavitt SM et al (2020) National mitigation potential from natural climate solutions in the tropics. Philos Trans R Soc Lond Ser B 375:20190126. https://doi.org/10.1098/rstb.2019.0126

Harris NL, Gibbs DA, Baccini A, Birdsey RA, De Bruin S, Farina M et al (2021) Global maps of twenty-first century forest carbon fluxes. Nat Clim Change 11:234-240. https://doi.org/10.1038/ s41558-020-00976-61-7

IPCC (2007) Climate change 2007: fourth assessment report of the intergovernmental panel on climate change. Synthesis report. In: S Solomon et al (eds). Cambridge University Press, New York

Johannsdottir L, McInerney C (2016) Calls for carbon markets at COP21: a conference report. J Clean Prod 124:405-407

Kerchner CD, Keeton WS (2015) California's regulatory forest carbon market: viability for northeast landowners. For Policy Econ $50: 70-81$

Kossoy A (2015) State and trends of carbon pricing 2015. World Bank Publications.

Kooten GC (2017) Forest carbon offsets and carbon emissions trading: problems of contracting. For Policy Econ 75:83-88

Li N (2016) Climate change strategies via forestry and carbon trading. Presented on June 6th, 2016 in Tengchong. China Green Carbon Foundation.

Manley B, Maclaren P (2012) Potential impact of carbon trading on forest management in New Zealand. For Policy Econ 24:35-40

Meyer DZ, Avery LM (2009) Excel as a qualitative analysis tool. Field Methods 21(1):91-112

Meyer-Ohlendorf N, Görlach B, Roberts E (2016) EU effort sharing decision after 2020: auctioning of AEAs.

New Zealand Forest Statistics (2019) Forest land under the emission trading scheme. https://www.mpi.govt.nz/forestry/new-zealandforests-forest-industry/forestry/new-zealands-forests-statistics/\#: $\sim:$ text $=$ The $\% 20$ total $\% 20$ planted $\% 20$ forest $\% 20$ standing,domin ant\%20species\%20in\%20New\%20Zealand. Accessed 12 Dec 2020.

Nowell LS, Norris JM, White DE, Moules NJ (2017) Thematic Analysis: striving to meet the trustworthiness criteria. Int J Qual Methods 16(1):1609406917733847

NVIVO, n.d. Import data from spreadsheets and text files. [Online] http://help-nv11 mac.qsrinternational.com/desktop/procedures/ import_data_from_spreadsheets_and_text_files.htm. Accessed 7 Oct 2019.

Parker C, Merger E, Streck C, Conway D, Tennigkeit T, Wilkes A (2014) The land-use sector within the post-2020 climate regime. http://norden.divaportal.org/smash/get/diva2:711029/FULLT EXT01.pdf. Accessed 7 Oct 2020.

RIFINITIV (2019) Review of carbon markets in 2019. https://www. refinitiv.com/content/dam/marketing/en_us/documents/reports/ global-carbon-market-emission-trading-system-review-2019.pdf. Accessed 27 Dec 2020.

Ristea C, Maness TC (2009) Opportunities, challenges and markets for forest carbon offset projects. For Chron 85(5):715-718

Richards KR, Huebner GE (2012) Evaluating protocols and standards for forest carbon-offset programs, Part A: additionality, baselines and permanence. Carbon Manag 3(4):393-410

Roppongi H, Suwa A, Puppim JA (2016) Innovating in sub-national climate policy: the mandatory emissions reduction scheme in Tokyo. Clim Policy 17(4):1-17

SFA (2010) State forestry administration initiates pilot carbon afforestation projects in China. http://www.forestry.gov.cn/portal/yzlzl/s/ 1662/content-451638.html. Accessed 12 Jan 2019. 
SFA (2014) Instructions on improving carbon forest project trading. http://www.forestry.gov.cn/main/72/content-675073.html. Accessed 25 Jan 2019.

Seddon N, Daniels E, Davis R, Harris R, Hou-Jones X, Huq S, Kapos V, Mace GM, Rizvi AR, Reid H, Roe D, Wicander S (2019) Global recognition of the importance of nature-based solutions to climate change impacts. Global Sustainability (in review) https:// www.preprints.org/manuscript/201810.0203/v3

United Nations (1998) Kyoto protocol to the United National Framework Convention on Climate Change. http://unfccc.int/resource/ docs/convkp/kpeng.pdf\#page $=12$. Accessed 08 Apr 2020 .

UNFCCC (2015a) Synthesis report on the aggregate effect of the intended nationally determined contributions. https://unfccc.int/ resource/docs/2015/cop21/eng/07.pdf. Accessed 21 July 2020.

UNFCCC (2015b) Conference of the parties, adoption of the Paris Agreement. https://unfccc.int/files/essential_background/conve ntion/application/pdf/english_paris_agreement.pdf. Accessed 21 July 2020.

Woolf NH, Silver C (2017) Orientation to NVivo. In: Qualitative analysis using NVivo. Routledge, pp 61-65

World Bank (2020) State and Trends of Carbon Pricing 2019, World Bank, Washington, DC.https://doi.org/10.1596/ 978-1-4648-1435-8
Xiaodong C (2016) The validation and verification of voluntary carbon emission reduction through forestry projects and case studies in China. Presented on June 7th, 2016 in Tengchong. CEC.

Zhang ZX (2015) Carbon emissions trading in China: the evolution from pilots to a nationwide scheme. Clim Policy 15(sup1):S104-S126

Zhang ZX (2015) Carbon emissions trading in China: the evolution from pilots to a nationwide scheme (April 1, 2015). Crawford School of Public Policy CCEP Working Paper 1503. https://doi. org/10.2139/ssrn.2741929

Zhou W, Gong P, Gao L (2017) A review of carbon forest development in China. Forests 8(8):295. https://doi.org/10.3390/f8080295

Publisher's Note Springer Nature remains neutral with regard to jurisdictional claims in published maps and institutional affiliations. 